\title{
The prevalence of psychiatric comorbidity and its relationship to the severity of alcohol dependence in the population of rural south India
}

\author{
Tangella Ravikanth ${ }^{1}$ and Sadia Sultan ${ }^{2^{*}}$ (D
}

\begin{abstract}
Background: Many international studies have reported a high prevalence of psychiatric comorbidity in alcoholdependent individuals and highlighted the clinical, prognostic, and treatment implications of such findings. However, there is a paucity of such information within the context of India. This study investigates the prevalence of psychiatric comorbidity in treatment-seeking alcohol-dependent individuals and its relationship with the severity of this dependence.
\end{abstract}

Result: This was a prevalence study conducted for a period of 1 year. Patients were identified from Mahbubnagar, a local area in rural south India, and recruited at outpatient deaddiction clinic of SVS hosital. Application for research ethics approval was approved. A consecutive sample of 100 inpatients diagnosed with alcohol dependence syndrome was recruited. The Mini-International Neuropsychiatric Interview was used to assess psychiatric comorbidity 2 weeks after detoxification. The severity of dependence was judged using the Severity of Alcohol Dependence questionnaire. One-hundred (male, $n=65$; female, $n=35$ ) alcohol-dependent patients were recruited. The mean age of participants was $41.9(\mathrm{SD}=9.3)$ years. Participants $(n=33,33 \%)$ had a co-occurring psychiatric disorder, the commonest being mood disorder $(n=18)$, which sub-divided into major depressive disorder $(n=8)$, dysthymia $(n=5)$, manic episode $(n=3)$, and hypomanic episode $(n=2)$, followed by anxiety disorders $(n=11)$ and then psychotic disorder $(n=4)$. The comorbid psychiatric disorders were significantly associated with the severity of dependence $(p=0.001)$ and longer duration of alcohol $(p=0.003)$ use.

Conclusion: This result emphasizes the need to thoroughly assess patients for possible under-identified dual diagnosis and provide treatments accordingly.

Keywords: Alcohol dependence, Alcohol use disorder, Comorbidity, Psychiatric illness, Dual diagnosis

\section{Background}

The co-occurrence of substance abuse and psychiatric disorders is a well-known fact. The Epidemiological Catchment Area (ECA) study is the largest survey of a general population $(n=20,000)$. The survey reported lifetime prevalence of alcohol dependence as $13.5 \%$, current prevalence as $4.8 \%$, and a wide range of comorbid psychiatric disorders such as schizophrenia/schizophreniform

\footnotetext{
* Correspondence: drsaddy2003@yahoo.com; https://www.uqu.edu.sa 2Department of Laboratory Medicine, College of Applied Medical sciences, Umm Al-Qura University, Abdiya, Makkah, Kingdom of Saudi Arabia Full list of author information is available at the end of the article
}

disorders $(1.5 \%)$, bipolar affective disorders (1.3\%), unipolar depression $(8.5 \%)$, and anxiety disorders $(14.6 \%)$ which comprise phobias at $12.6 \%$, agoraphobia at $5.2 \%$, social phobia at $2.8 \%$, simple phobia at $10 \%$, panic disorder at $1.6 \%$, panic disorder with agoraphobia at $0.5 \%$, obsessive-compulsive disorder $(\mathrm{OCD})$ at $2.5 \%$, and antisocial personality disorder $2.6 \%$ [1].

The estimated prevalence of dual diagnosis was 30 $60 \%$ as reported by the National Comorbidity Survey (NCS). The probability of receiving specialized mental health services is higher for people with a comorbid psychiatric disorder and alcohol dependence syndrome 
(ADS) (41\%) than for those who have alcohol abuse or dependence alone (25\% and $24 \%$, respectively) [2]. Comorbid mental health and substance use disorders (SUD), commonly referred to as "dual diagnosis" or simply "comorbidity," are associated with significant economic and human costs. People with comorbidity have been found to be more severely ill, difficult to manage, non-compliant with medication, have fewer social supports and financial resources, and are at a higher risk of medical problems like HIV, hepatitis [3]. The comorbidity tends to co-occur in many patients and is higher than in the general population. This has been noted in both population-based $[1,2,4,5]$ as well as clinic-based studies across the world $[6,7]$. Evidence suggests that between $45 \%$ and $80 \%$ of alcoholics, either in the community [8] or in clinical populations $[9,10]$, suffer from another psychiatric disorder. Hertz et al. [9] found additional psychopathology in 54\% of ADS patients. Among those with comorbid diagnoses, 35\% had one, $10 \%$ had two, and $55 \%$ had three or more diagnoses.

\section{General prevalence of comorbid psychiatric disorders}

According to Hesselbrock et al. [11], 66\% of patients met criteria for current psychiatric disorder involving other substance abuse (9\%), depression (23\%), phobia (6\%), mania (2\%), somatization (1\%), and schizophrenia (2\%). In a community study, Weiss et al. [10] observed various co-occurring disorders which included major depression (44\%), bipolar disorder (6\%), generalized anxiety (9\%), phobia (3\%), and misuse of drugs other than alcohol (12\%). Although the institutionalized population represented only $1.3 \%$ of the total population, the overall rate of psychopathology was higher than that existing within the community. The lifetime prevalence rate for any substance abuse and mental disorder in the institutionalized population was more than twice that found in the community population [10]. Based on ECA data, the psychiatric comorbidities are as follows: mania 6.2 times more and schizophrenia 4.0 times more. There is only a mild increase in major depressive disorder among alcoholics [12]. Psychiatric comorbidities varied between $40 \%$ and $70 \%$ in most studies conducted in the last 20 years $[9,13]$. Among various comorbidities in male alcoholics, Powell et al. [14] reported $42 \%$ major depressive disorder, $20 \%$ mania, and $20 \%$ anti-social personality disorder.

\section{General prevalence of comorbid psychiatric disorders in Indian population}

A meta-analysis of 20 studies estimated the prevalence of psychiatric morbidity in India as 56/1000 population [15]. Baxter et al. [16] reported a prevalence of $0.2 \%$ schizophrenia, $0.1 \%$ bipolar, $2 \%$ depressive disorders, and $0.2 \%$ anxiety disorders in the general population. Considering the prevalence of psychiatric comorbidity in SUD, a retrospective study that included 5283 patients found $13.2 \%$ dual diagnosis with mood disorder (42.2\%) being most common. The most common SUD present in patients with dual diagnosis were alcohol and nicotine followed by opioid [17]. Another retrospective study which included 289 patients with dual diagnosis reported nicotine and alcohol as the most common substances followed by opioid to be associated with comorbidities and MDD being the most commonly reported disorder (24.9\%) [18]. Most cross-sectional studies have shown a prevalence rate between $25 \%$ and $80 \%$ with depression being the most commonly reported disorder [19-22] in ADS. In a case-control study, prevalence rates of psychiatric comorbidity in ADS and controls were found to be $92 \%$ and $12 \%$, respectively The most common disorders were depression, antisocial personality disorder (ASPD), and phobia [22]. A study by Vohra et al. [23] reported 76.6\% comorbid Axis 1 and $40 \%$ Axis 2 disorders. The most common was major depression $52.1 \%$ followed by dysthymia $13.0 \%$, brief psychotic disorder $13.0 \%$, and alcohol-induced psychotic disorder $0.5 \%$. Among Axis 2 disorders, the most common was cluster B (58.3\%) followed by cluster A (16.6\%) and cluster C (16.6\%). According to Gauba et al. [24], 86.8\% had comorbid Axis 1 and Axis 2 disorders. The prevalence of affective disorders was $28.75 \%$, the most common being depressive episode (15\%) followed by dysthymia (8.75\%), bipolar disorder $(2.5 \%)$, mania (1.25\%), mania with psychotic symptoms $(1.25 \%)$, and schizophrenia $2.5 \%$. The gender difference between males and females found increased severity of ADS in males whereas more comorbid disorders were reported in females with MDD being the most commonly reported comorbidity in both genders [25].

\section{Prevalence of specific comorbid psychiatric disorders Depression}

A 12-month follow-up study by Nunes et al. [26] in patients seeking treatment for both alcohol and depression $(n=110)$ found that in substancedependent patients, both DSM-IV primary and substance-induced major depressive disorder (MDD) predicted future depression. Eighty-eight percent of the patients experienced a depressed mood for at least 1 week, and 57\% experienced MDD. A study looking at the effect of MDD on the progression of substance dependence found that patients with current substance-induced MDD were less likely to remit from dependence than patients with no baseline MDD. A history of MDD prior to the lifetime 
onset of substance abuse also reduced the likelihood of remission relative to the absence of such a history. MDD during sustained abstinence predicted dependence relapse after hospital discharge compared with those without MDD [27]. When substanceinduced mood disorders are identified, they are likely to disappear soon after abstinence, a situation not seen with independent depressive episodes. Thus, overall continued abstinence in alcoholics is likely to be associated with a decrease in depressive symptoms $[28,29]$. In a 1-year follow-up of hospitalized alcohol-dependent male patients $(n=239), 4 \%$ developed depressive episodes while drinking heavily, whereas $2.1 \%$ demonstrated MDD independent of heavy alcohol intake [30].

\section{Anxiety disorders}

A strong association is noted between generalized anxiety disorder (GAD) and substance use disorder (SUD) [30, 31]. High rates of comorbidity of GAD and SUD have been frequently reported in clinical [32] and community [1, 2, 33] samples and have been associated with worse outcomes than independent disorders. Among individuals with alcohol use disorders, those with comorbid anxiety have a greater severity of illness [34] by comparison with those with alcohol use disorders alone, and are more disabled, drink more heavily, have worse social adjustment and outcome and greater number of hospitalization [35]. A long-term follow-up study found that comorbid SUD among individuals with GAD significantly decreased the likelihood of recovery from GAD and significantly increased the risk of recurrence of this disorder [36]. The risk of a comorbid substance use disorder in patients with panic disorder was found to be 2.4 times higher than that in the general population [37]. A study of in-patients with alcohol dependence showed a prevalence of $24.7 \%$ social phobia, $30.6 \%$ specific phobia, $19.3 \%$ generalized anxiety disorder, $5 \%$ obsessive-compulsive disorder, $4.6 \%$ posttraumatic stress disorder, $2 \%$ panic disorder with agoraphobia, and $22.2 \%$ any anxiety disorder induced by alcohol [38]. Similarly, Bowen et al. [39] studied a group of 48 in-patient alcoholics finding that $44 \%$ had anxiety disorders, 24\% had agoraphobia, social and mixed phobias.

\section{Psychotic disorders}

Epidemiologic studies have revealed that the odds of having alcohol dependence were 2.7 to 3 times higher in patients with non-affective psychosis [40]. A population-based study $(n=8028)$ showed that the lifetime prevalence was $0.41 \%$ for alcoholinduced psychotic syndrome [41]. Past clinic-based studies have shown that $2-7 \%$ of patients with alcohol dependence had alcohol hallucinosis [42] and 5$11 \%$ had delirium tremens [42, 43]. Substance use in schizophrenic patients was associated with poor social function, symptom exacerbation, frequent hospitalization, medication noncompliance, and poor treatment response [44].

\section{Bipolar disorder}

The ECA data for alcohol abuse/dependence in patients with bipolar I disorder reported a prevalence rate of $46 \%$. In the data from National Epidemiologic Survey on Alcohol and Related Conditions (NESARC) [45], 54\% of respondents who met the criteria for bipolar disorder also reported as having alcohol use disorder.

\section{Severity of dependence and association with psychiatric comorbidity}

Patients with comorbidity were more likely to suffer from poor health and functional impairment [46] and the progression of alcoholism in patients without comorbidity was significantly milder. Comorbidity was associated with earlier onset of dependence, higher volume of daily alcohol intake, and greater severity of dependence in patients with both Axis 1 and Axis 2 comorbidities [10,47-49]. Studies have demonstrated a positive relationship between the severity of alcohol dependence and the prevalence of additional psychiatric symptom patterns [47, 48]. Subodh et al. [49] found a $32.4 \%$ prevalence of dual diagnosis in SUD patients with alcohol being the most common substance associated with other comorbidities followed by opioids. Affective disorder was $12.3 \%$ followed by anxiety disorder $11.2 \%$ and psychotic disorder 5\%. Furthermore, this study showed no significant association between the duration of substance use and comorbidity. A study was done on 35 females to demonstrate the relationship between severity of alcohol dependence and the presence of comorbid psychiatric disorder reported 57.14\% comorbid Axis 1 disorders. MDD 34\% was the most common followed by dysthymia 11\%, PTSD $9 \%$, adjustment disorder $8 \%$, and mania 3\%. Furthermore, the study found no significant correlation between the age of initiation, regular use, and the severity of dependence with the presence of comorbidity [50]. High rates of psychiatric comorbidity exist in ADS patients yet the extent of the problem is not being addressed in India as there is a paucity of studies focusing on the severity of alcohol dependence and the presence of comorbidity. This study attempts to address this issue and investigate the association between the severity of dependence 
and psychiatric comorbidity. In this respect, this study differs from previous studies in terms of sample selection where ADS patients alone, i.e., no SUD patients, are selected. Moreover, the sample size in this study was larger than that of previous studies and was drawn from a rural area of southern India.

\section{The objectives}

The objectives of this study are the following:

1. To determine the prevalence and type of psychiatric comorbidity in alcohol-dependent in-patients

2. To examine the severity of alcohol dependence and psychiatric comorbidity

\section{Methods}

\section{Study design}

This was a prevalence study conducted for a period of 1 year from 1 January 2016 to 31 December 2016.

\section{Study setting}

The study was conducted in the Psychiatry Department (deaddiction unit) at Sri Venkata Swami (SVS) medical college and hospital, Mahbubnagar, Telangana, India. Approval for the study was granted by the scientific ethical committee of SVS medical college and hospital.

\section{Participants}

The study sample was collected from in-patients at the Psychiatry Department at SVS medical college and hospital and comprised 100 in-patients diagnosed by the primary investigator as ADS as per International Classification of Mental and Behavioural Disorders - Research and Diagnostic Criteria (ICD-10 RDC).

\section{Inclusion criteria}

Patients must be aged between 18 and 65 years, fulfill the diagnostic criteria of alcohol dependence of ICD-10 RDC classification, are physically and mentally fit, are willing to complete the necessary questionnaires, and are capable of giving informed consent.

\section{Exclusion criteria}

Participants are excluded if they take a psychoactive substance or any medication which can produce cognitive and other psychological defects other than nicotine and caffeine. Also excluded are patients with organic mental disorders and those who did not complete detoxification of at least 2 weeks duration or are in an altered mental state despite detoxification.

The study sample comprised all participants fulfilling the eligibility criteria and willing to take part in the study over the study period of a year.
Table 1 Sociodemographic data and clinical characteristics of study subjects

\begin{tabular}{|c|c|c|c|c|c|}
\hline \multicolumn{2}{|c|}{ Socio demographic variables } & \multicolumn{2}{|c|}{$\begin{array}{l}\text { Psychiatric } \\
\text { comorbidity }\end{array}$} & \multirow[t]{3}{*}{ Total } & \multirow[t]{3}{*}{$p$ value } \\
\hline & & \multirow{2}{*}{$\begin{array}{l}\text { Absent } \\
67\end{array}$} & \multirow{2}{*}{$\begin{array}{l}\text { Present } \\
33\end{array}$} & & \\
\hline & & & & & \\
\hline \multirow[t]{3}{*}{ Age (years) } & $15-30$ & 14 & 8 & 22 & \multirow{3}{*}{$\begin{array}{l}0.888 \\
\text { (N.S) }\end{array}$} \\
\hline & $31-45$ & 32 & 16 & 48 & \\
\hline & $>45$ & 21 & 9 & 30 & \\
\hline \multirow[t]{2}{*}{ Sex } & Male & 43 & 22 & 65 & \multirow{2}{*}{$\begin{array}{l}0.806 \\
\text { (N.S) }\end{array}$} \\
\hline & Female & 24 & 11 & 35 & \\
\hline \multirow{5}{*}{$\begin{array}{l}\text { Socio-economic } \\
\text { status }\end{array}$} & Upper & 1 & 0 & 1 & \multirow{5}{*}{$\begin{array}{l}0.829 \\
\text { (N.S) }\end{array}$} \\
\hline & $\begin{array}{l}\text { Upper } \\
\text { middle }\end{array}$ & 6 & 3 & 9 & \\
\hline & $\begin{array}{l}\text { Lower } \\
\text { middle }\end{array}$ & 15 & 5 & 20 & \\
\hline & Upper lower & 31 & 16 & 47 & \\
\hline & Lower & 14 & 9 & 23 & \\
\hline \multirow[t]{2}{*}{ Employment } & Employed & 41 & 13 & 54 & \multirow[t]{2}{*}{0.040} \\
\hline & Unemployed & 26 & 20 & 46 & \\
\hline
\end{tabular}

Unemployment was significantly associated with the presence of psychiatric comorbidity

\section{Study procedure}

A consecutive sample of 100 ADS patients admitted in Psychiatry Department at SVS Medical College \& Hospital was selected. Inclusion and exclusion criteria were assessed. Informed consent in writing was obtained before patients were included in the study. A data collection sheet was used to record sociodemographic data, general health, and alcohol dependence characteristics like age of initiation of drinking, duration of drinking, frequency of attempts to abstain, and the total duration of abstinence. The English version of the Mini-International Neuropsychiatric Interview (MINI Plus) [51] was used to evaluate previous and current psychiatric disorders, and the diagnosis was confirmed by using ICD-10 RDC after 2 weeks of admission to limit the interference from withdrawal symptoms. Severity of Alcohol Dependence Questionnaire (SADQ) was used to measure the severity of dependence.

Table 2 Distribution among study population based on the severity of alcohol dependence

\begin{tabular}{lc}
\hline Severity of alcohol dependence & $N$ \\
\hline Mild & 48 \\
Moderate & 42 \\
Severe & 10 \\
Total & 100 \\
\hline
\end{tabular}




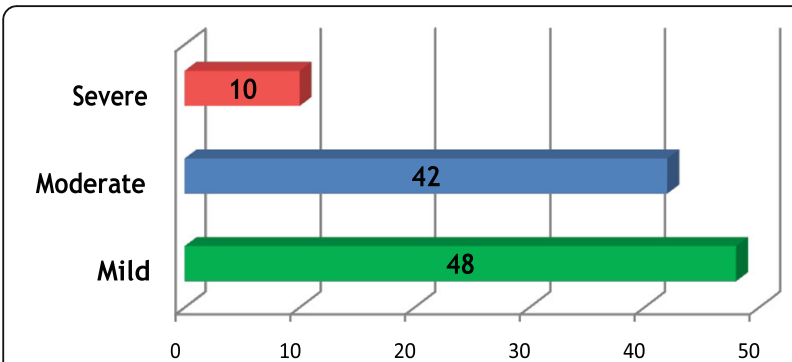

Fig. 1 Severity of alcohol dependence

\section{Data analysis}

Sample size was calculated by the formula $N=\mathrm{z} 2 \mathrm{PQ} /$ L2, where $N=$ sample size, $Z=1.96$ at 95\%CI, $P$ (prevalence) $=8 \%$ (occurrence of psychiatric disorders) as found in the study, $Q=100-8=98 \%$, and $L=6 \%$ precision; therefore, $N=3.84 \times 97 \times 3 / 6 \times 6$ $=78.5 \%$, making to near value, considering the $20 \%$ non-response rate, and the total sample size taken was 100 . The power of the study is $100-6=94$. Data analysis was carried out using the Statistical Package for Social Sciences (SPSS). The data were normally distributed and hence parametric tests were used. All data except age were categorical variables and so $t$ test was done for age and chi-squared test for all other data. The analysis took a $p$ value $<0.05$ to be statistically significant.

\section{Result}

Most subjects $(n=48)$ belonged to the age group of $31-45$ years, $65 \%$ were males and $35 \%$ females (Table 1). The majority (47\%) belonged to upper lower socioeconomic status. Exactly $54 \%$ of the subjects were employed and 46\% unemployed (Table 1). In the study population, age, sex, and socioeconomic status had no significant influence on the presence or absence of psychiatric comorbidity. Nevertheless, psychiatric comorbidity is significantly greater $(p=0.04)$ in those who are unemployed than those who were employed (Table 1). Considering the severity of dependence, $48 \%$ had mild dependence, and $42 \%$ had moderate dependence, while $10 \%$ had severe dependence (Table 2 and Fig. 1). Thirty-three percent of the sample was found to have a comorbid psychiatric disorder (Table 3 and Fig. 2). The most common psychiatry comorbidity was mood disorder (18\%) followed by anxiety disorder (11\%) and psychotic disorder (4\%) (Table 4

Table 3 Distribution among study population based on the presence or absence of psychiatric comorbidity

\begin{tabular}{lll}
\hline $\begin{array}{l}\text { Psychiatric comorbidity } \\
\text { present }\end{array}$ & $\begin{array}{l}\text { Psychiatric comorbidity } \\
\text { absent }\end{array}$ & Total \\
\hline$N 33$ & 67 & 100 \\
\hline
\end{tabular}

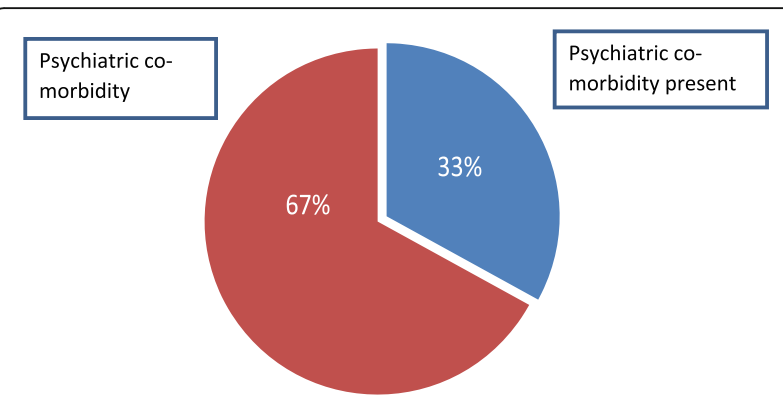

Fig. 2 Psychiatric comorbidity

and Fig. 3). Among the mood disorders, the most common was MDD (8\%). GAD at $6 \%$ was the most common among the anxiety disorders and brief psychotic disorder at $3 \%$ was the most common among psychotic disorders (Table 4 and Fig. 4). A comparison of patients with and without psychiatric comorbidity in relation to alcohol dependence characteristics showed no association with age of initiation of drinking or the frequency or duration of abstinence, although there was a significantly greater occurrence of psychiatric comorbidity $(p=0.03)$ in those with longer duration of drinking (Table 5). It seemed that psychiatric comorbidity is significantly greater $(p=0.001)$ in those with a higher severity of alcohol dependence (Table 6 and Fig. 5). However, there existed no such association between this type of comorbidity and severity of dependence (Table 7 and Fig. 6)

\section{Discussion}

This study focused on determining the prevalence of psychiatric comorbidity among alcohol-dependent subjects and its association with severity of dependence. The majority of the study subjects (ADS patients) were aged between 31 and 45 years. This was comparable with the Epidemiological Catchment Area

Table 4 Depicting the presence of specific comorbid psychiatric disorder in study subjects

\begin{tabular}{llll}
\hline Type of psychiatric comorbidity & $N$ & Specific disorder & $N$ \\
\hline Mood disorders & 18 & Major depressive disorder & 8 \\
& & Dysthymia & 5 \\
& & Manic episode & 3 \\
& & Hypomanic episode & 2 \\
Anxiety disorders (neurotic & 11 & Generalized anxiety disorder & 6 \\
stress-related and somatoform & & Adjustment disorder & 3 \\
disorders) & & Panic disorder & 2 \\
Psychotic disorders & 4 & Brief psychotic disorder & 3 \\
& & Schizophrenia & 1 \\
Total & 33 & Total & 33 \\
\hline
\end{tabular}




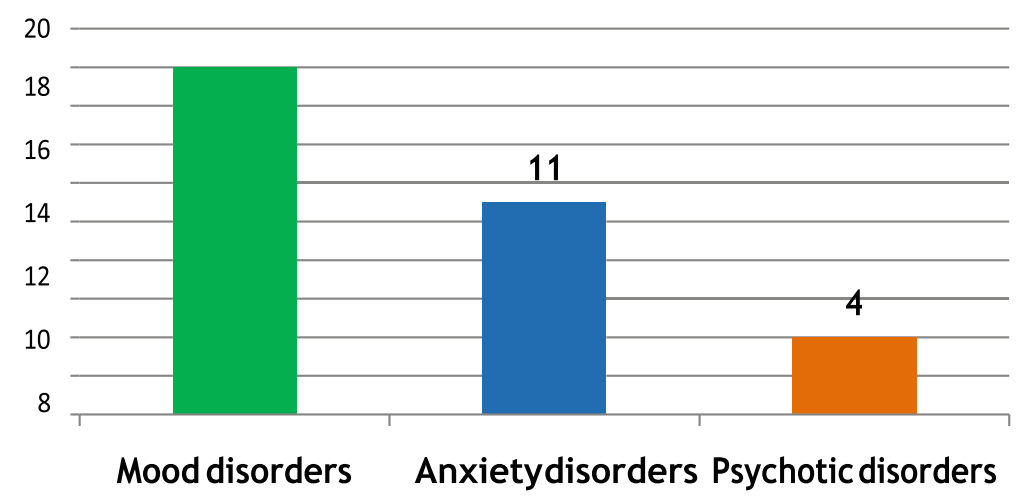

Fig. 3 Types of psychiatric comorbidity

(ECA) Study [1] which showed that lifetime prevalence rates for alcoholism tend to peak between ages of $30-44$ years. In the sample, $35 \%$ patients were female and 65\% were male. Large US-based epidemiological studies done by Hasin et al. [33] and Kessler et al. [2] showed higher rates of alcohol dependence in women at $52 \%$ and $51 \%$, respectively, when compared with the present study. The reason for this relatively lower prevalence might be cultural prohibitions and reduced liberalization of women in India than in Western countries.

\section{General prevalence of comorbid psychiatric disorders}

In the current study, psychiatric comorbidities were present in $33 \%$ of the population while the majority of the sample (67\%) had no comorbid psychiatric disorders. The current study showed lower rates of comorbidities when compared to other studies that reported a prevalence rate between 25-80\% [19-22]. The psychiatric comorbidity in the current study is comparable to $47 \%$ as reported by Singh et al. [22] The variability in rates of comorbidity in different studies is explained by settings, patient population, assessment tools used, and timing of the diagnostic interviews in relation to withdrawal effects. Moreover, some studies which showed higher rates included Axis 2 disorders which were not included in the present study.

Prevalence of specific comorbid psychiatric disorders Among the psychiatric disorders, the most common was mood disorder (18\%) followed by anxiety disorders $(11 \%)$ and psychotic disorders (4\%). This is consistent with the findings of most studies [14-21]. However, ECA [1] have reported anxiety disorder as

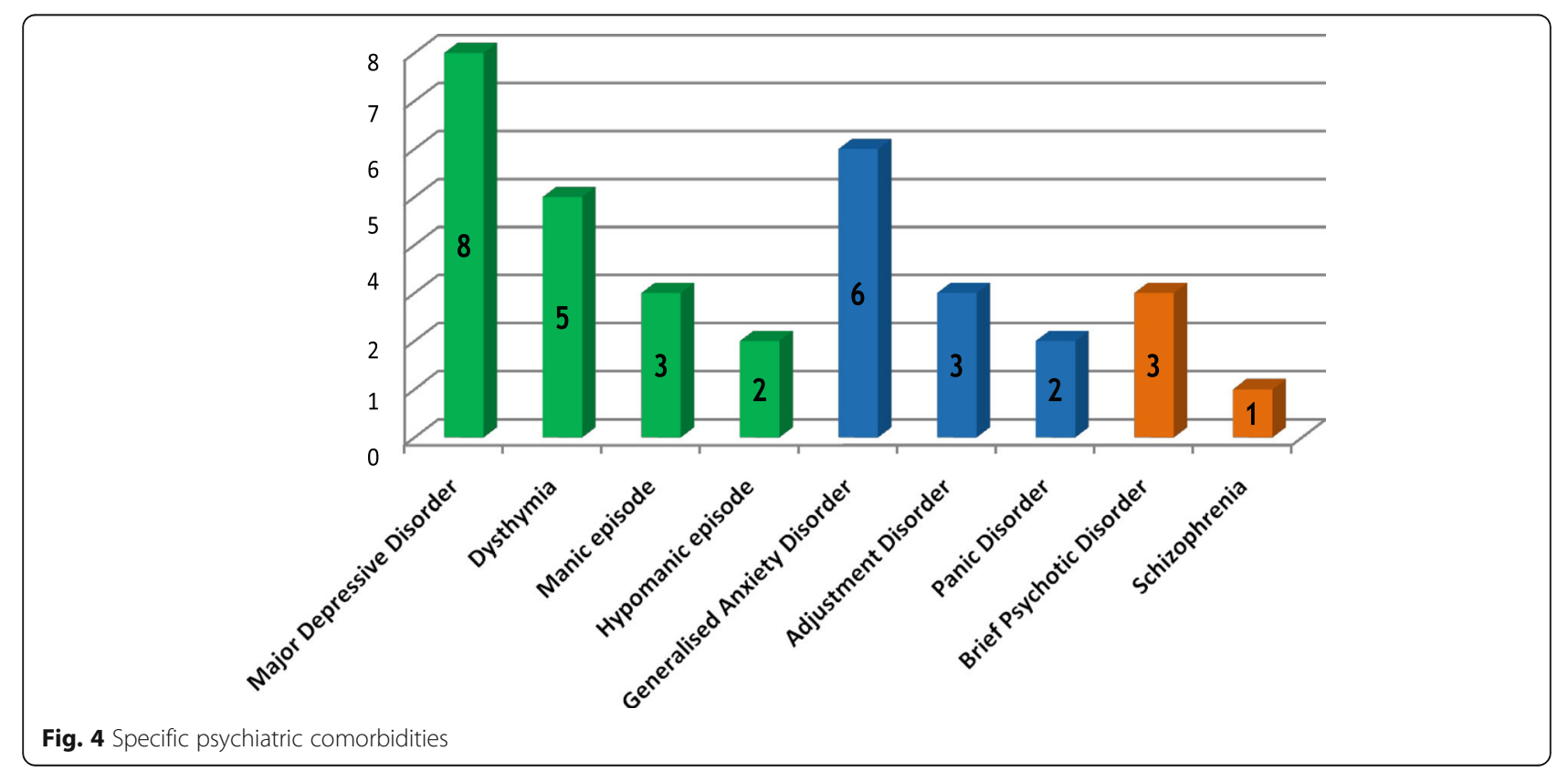


Table 5 Comparison of patients with and without psychiatric comorbidity in relation with alcohol dependence characteristics

\begin{tabular}{|c|c|c|c|c|c|}
\hline \multicolumn{2}{|c|}{ Alcohol dependence characteristics } & \multicolumn{2}{|c|}{ Psychiatric comorbidity } & \multirow[t]{3}{*}{ Total } & \multirow[t]{3}{*}{$p$ value } \\
\hline & & \multirow{2}{*}{$\begin{array}{l}\text { Absent } \\
67\end{array}$} & \multirow{2}{*}{$\begin{array}{l}\text { Present } \\
33\end{array}$} & & \\
\hline & & & & & \\
\hline \multirow[t]{2}{*}{ Age of initiation (years) } & Mean & 20.63 & 17.30 & - & 0.581 \\
\hline & Standard deviation & 4.661 & 4.959 & - & \\
\hline \multirow[t]{5}{*}{ Duration of drinking } & $0-10$ years & 7 & 6 & 13 & 0.033 \\
\hline & $11-20$ years & 32 & 8 & 40 & \\
\hline & $21-30$ years & 12 & 11 & 23 & \\
\hline & $31-40$ years & 11 & 2 & 13 & \\
\hline & $41-50$ years & 5 & 6 & 11 & \\
\hline \multirow[t]{3}{*}{ Frequency of abstinence } & 0 times & 11 & 6 & 17 & 0.386 (N.S) \\
\hline & $1-2$ times & 45 & 18 & 63 & \\
\hline & $3-5$ times & 11 & 9 & 20 & \\
\hline \multirow[t]{4}{*}{ Duration of abstinence } & 0 months & 12 & 6 & 18 & 0.995 (N.S) \\
\hline & $1-2$ months & 21 & 10 & 31 & \\
\hline & 3-12 months & 27 & 13 & 40 & \\
\hline & $>12$ months & 7 & 4 & 11 & \\
\hline
\end{tabular}

The above table is showing that the duration of drinking was significantly associated with the presence of psychiatric comorbidity

the commonest disorder. This contrary finding could be due to the fact that ECA was a community-based study and that these disorders do not present at a hospital.

\section{Mood disorders}

Among the mood disorders, the commonest was MDD (8\%) which is similar to many Indian studies $[17-20,22$, 23] followed by dysthymic disorder (5\%) and bipolar disorders (5\%). Earlier Western studies also reported MDD as the most common comorbidity in ADS [10, 14]. However, $8 \%$ is less when compared to most studies which reported the prevalence of depressive disorder in a range of $14-42 \%$ [18-24], 0.4 to $13 \%$ (dysthymia) [9, 10, 24] and 2 to $22 \%$ (bipolar disorder) $[9,11,14,24]$.

\section{Anxiety disorders}

In the present study, anxiety disorders (11\%) were the second most common type of psychiatric comorbidity.

Table 6 Comparison of patients with and without psychiatric comorbidity in relation with the severity of alcohol dependence

\begin{tabular}{|c|c|c|c|c|c|}
\hline & & \multicolumn{2}{|c|}{$\begin{array}{l}\text { Psychiatric } \\
\text { comorbidity }\end{array}$} & \multirow[t]{3}{*}{ Total } & \multirow[t]{3}{*}{$p$ value } \\
\hline & & Absent & Present & & \\
\hline & & 67 & 33 & & \\
\hline \multirow[t]{3}{*}{ Severity of dependence } & Mild & 42 & 6 & 48 & \multirow[t]{3}{*}{0.001} \\
\hline & Moderate & 23 & 19 & 42 & \\
\hline & Severe & 2 & 8 & 10 & \\
\hline
\end{tabular}

A significant association was found between the severity of dependence and the presence of psychiatric comorbidity
The most common anxiety disorder being GAD (6\%) followed by adjustment disorder (3\%) and panic disorder $(2 \%)$. Prevalence rates of anxiety disorders in our study were low by comparison with studies by Bowen [39] and Guba et al. [24] which reported 44\% and $45 \%$, respectively. However, our findings are comparable to $14 \%$ as reported by Singh et al. [22]. Most of the above studies have higher rates than this study which shows a lower prevalence of overall psychiatric comorbidity in the study sample.

\section{Psychotic disorders}

In the present study, psychotic disorders were found in $4 \%$. Three percent had brief psychotic disorder and $1 \%$ had schizophrenia, which is less when compared to $13 \%$ as reported by Vohra et al. [23]. Other studies also have such low rates $[1,2,11,24,25]$ partly due to the fact that such patient population, despite a higher known association with substance use disorders, is seldom seen in deaddiction settings. We included only those patients who attended our deaddiction unit, many patients with schizophrenia-alcoholism comorbidity might have been attending our general psychiatry department for the treatment of schizophrenia and hence could have been excluded from this study.

Few authors have, however, been skeptical about such high rates of psychiatric comorbidity associated with alcohol seen in the abovementioned studies. A minimum period of 3 weeks abstinence from alcohol appears to be necessary to give consistent dual diagnosis [52]. 


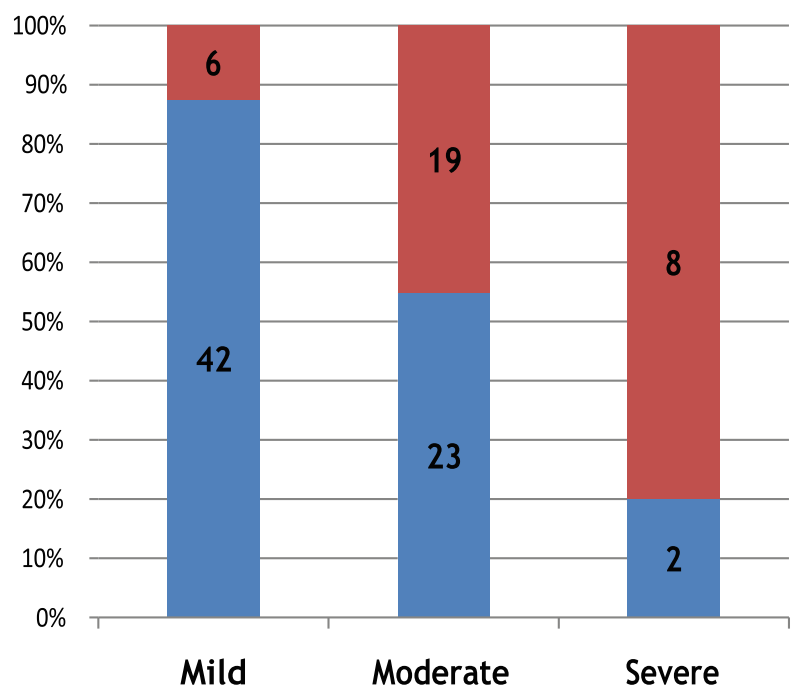

With psychiatric co-morbidity

Withoutpsychiatricco- morbidity

Fig. 5 Presence of psychiatric comorbidity in relation with the severity of dependence

A study in hospitalized alcoholics found the prevalence of depression in the index episode of alcoholism to be $30.2 \%$ when assessed at admission while only $20 \%$ of those initially diagnosed as depressed continued to fulfill the criteria for major depression after 10-14 days of abstinence [53]. The rest might have been alcohol-induced affective disorder. Similar results were found among anxiety disorders [54]. In line with considering the distressing psychiatric syndromes among alcoholics as clinically relevant, but temporary conditions, Schuckit et al. [55] used a time-line approach to distinguish psychiatric syndromes that occurred in the context of substancerelated disorders from those that appear to have developed independently of alcohol dependence. They found no evidence to suggest that alcoholism was associated with increased rates of independent major depressive disorder (11.5\%), OCD (1.3\%), or agoraphobia (1.6\%) compared to control (15.9\%, $0.9 \%$, and $0.9 \%$, respectively). However, alcoholdependent subjects had a twofold increased risk for bipolar illness $(2.3 \%$ vs. $1.0 \%)$ and threefold risk for panic disorder $(4.2 \%$ vs. $1.0 \%)$ and social phobia (3.2\% vs. $1.4 \%)[55]$.
The various studies reviewed above had cross-sectional designs and assessments were made after few days of admission (between 5 to 14 days), allowing for the effect of alcohol to subside, and also taking into account the withdrawal states that may confound the clinical presentation. The current study also followed this line of assessment interviewing the patients after 15 days of detoxification. The use of benzodiazepines during the detoxification phase subdued the intensity of withdrawal symptoms that may have otherwise confounded our assessment, thus allowing the interview to be conducted at an earlier date than the stipulated 4 weeks required by DSM-IV before confidently diagnosing another psychiatric disorder, not due to alcohol intoxication or withdrawal [52].

In the current study, no significant association was found between various socio-demographic variables and the presence of psychiatric comorbidity except for unemployment. When patients with and without psychiatric illness were compared, patients with psychiatric illnesses had higher rates of unemployment similar to the study by Cherkunath et al. [21]. The high rates of unemployment might be due to multiple reasons such as greater chances of impaired work performance or absenteeism, excessive time and

Table 7 Comparison of types of psychiatric comorbidity in relation with severity of dependence

\begin{tabular}{|c|c|c|c|c|c|c|}
\hline & & \multicolumn{3}{|c|}{ Type of comorbidity } & \multirow[t]{2}{*}{ Total } & \multirow[t]{2}{*}{$p$ value } \\
\hline & & Mood disorders & Anxiety disorders & Psychotic disorders & & \\
\hline Total & & 18 & 11 & 4 & 33 & \\
\hline \multirow[t]{3}{*}{ Severity of dependence } & Mild & 2 & 3 & 1 & 6 & $0.835(\mathrm{~N}, \mathrm{~S})$ \\
\hline & Moderate & 11 & 6 & 2 & 19 & \\
\hline & Severe & 5 & 2 & 1 & 8 & \\
\hline
\end{tabular}

In the study population, no significant relationship exists between the type of psychiatric comorbidity and severity of alcohol dependence 


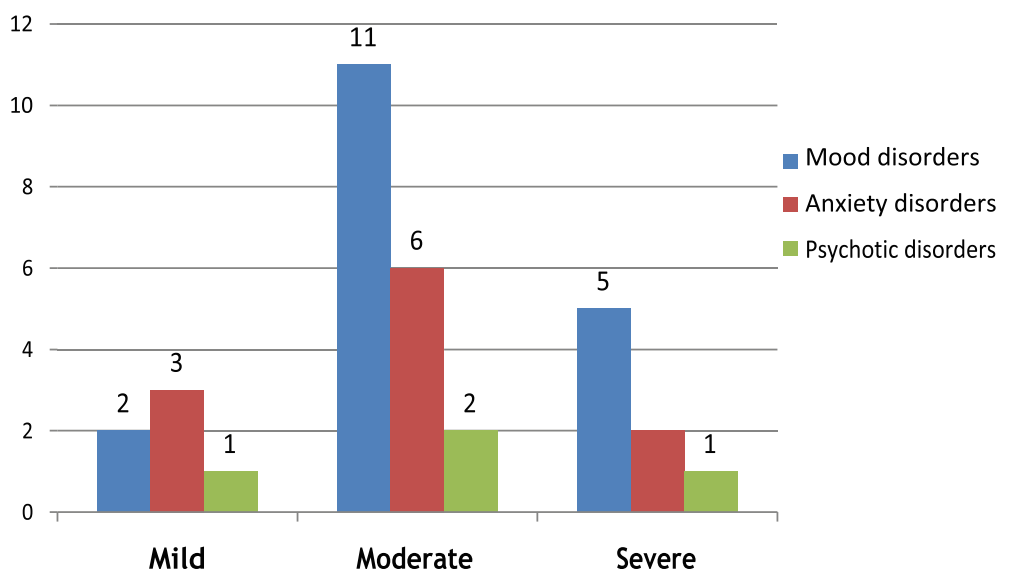

Fig. 6 Relationship between severity of dependence and the presence of specific psychiatric disorder

money spent over alcohol use, and frequent hospitalizations seen with alcohol dependence with psychiatric comorbidity more than those without.

\section{Severity of dependence and association with psychiatric comorbidity}

Our study found a significant association of duration of drinking and severity of dependence with the presence of comorbidity. No association was found with other variables such as age of initiation, frequency, or duration of abstinence. These findings are similar to many earlier studies which reported an association between duration of drinking and severity of dependence with both Axis 1 and Axis 2 comorbidities [9, 56-58]. On the contrary, Malik et al. [48] reported no significant correlations between the presence of comorbidity and the duration of drinking or the severity of dependence. Similarly, Sudodh et al. [49] reported no significant correlation between the duration of substance use and the presence of comorbidity.

\section{Conclusion}

To conclude, this study provides an insight into the prevalence of psychiatric comorbidity in alcoholdependent individuals and its increasing probability with increasing severity of dependence, thereby emphasizing the importance of a thorough evaluation for the probability of dual diagnosis and providing treatment as needed. The study was limited to an in-patient population in a hospital setting; hence, results cannot be generalized to a community setting. Mini Plus scale could not differentiate between independent and alcohol-induced psychiatric disorders. Psychiatric disorder could not be placed in a time frame (lifetime, past, current diagnosis). The study was not designed to take into account Axis 2 disorders which have been done in many previous studies. Future studies on comorbidity in alcohol dependence will focus on a larger sample size including both in- and outpatients and longitudinal assessments of subjects for psychopathology, noting how the prevalence of psychiatric disorders change over time and affect treatment response, dropout rate, outcome, and whether or not the coexisting psychopathology influences the treatment-seeking behavior of alcoholics.

\section{Abbreviations \\ ADS: Alcohol dependence syndrome; ASPD: Antisocial personality disorder; DSM-IV: Diagnostic and Statistical Manual of Mental Diorders - fourth revision; ECA: Epidemiological Catchment Area study; GAD: Generalized anxiety disorder; ICD-10 RDC: International Classification of Mental and Behavioural Disorders - Research and Diagnostic Criteria; MDD: Major depressive disorder; MINI Plus: Mini-International Neuropsychiatric Interview; NCS: National Comorbid Survey; NERAC: National Epidemiologic Survey on Alcohol and Related Conditions; OCD: Obsessive-compulsive disorder; SADQ: Severity of Alcohol Dependence Questionnaire; SUD: Substance use disorder}

\section{Acknowledgements}

The authors wish to thank Dr. Sharband Raj for his guidance in the execution of this study and the Department of Psychiatry, SVS Medical College and Hospital, MahboobNagar, Telengana, India, for their support of this work. We would also like to thank Dr. Grace Lindsay (Professor, Nursing Department, Umm Al-Qura University) for her guidance, writing assistance, and technical editing).

\section{Authors' contributions}

Dr. TR-MD, persuing DM child psychiatry at Department of Psychiatry, PGIMER, Chandigarh - had substantial contributions to the conception, design of the work, acquisition, analysis, and interpretation of data arising in the course of the study. Dr. SS-MD in psychiatry, assistant professor, Department of Lab. Medicine, College of Applied Medical Sciences, Umm Al Qura University, Makkah, KSA—had substantial contributions to the conception or design of the work and gave the final approval of the version to be published. Agreement to be accountable for all aspects of the work in ensuring that questions related to the accuracy or integrity of any part of the work are appropriately investigated and resolved. All authors have read and approved the manuscript.

Funding

Not applicable 


\section{Availability of data and materials}

Generated data during this study is included in supplementary information files.

\section{Ethics approval and consent to participate}

"The study was approved by the scientific ethical committee of research, SVS medical college and hospital (REF: SVSMC/IEC-022/2014). The written informed consent was taken from the patients before recruiting them in the study."

\section{Consent for publication}

Not applicable

\section{Competing interests}

The authors declare that they have no competing interests.

\section{Author details}

'Department of Child Psychiatry, Post Graduate Institute of Medicine and Research, Chandigarh, India. ${ }^{2}$ Department of Laboratory Medicine, College of Applied Medical sciences, Umm Al-Qura University, Abdiya, Makkah, Kingdom of Saudi Arabia.

Received: 6 August 2019 Accepted: 11 November 2019

Published online: 02 January 2020

\section{References}

1. Regier DA, Farmer ME, Rae DS, Locke BZ, Keith SJ, Judd LL et al (1990) Comorbidity of mental disorders with alcohol and other drug abuse. Results from the Epidemiologic Catchment Area (ECA) Study. Jama. 264(19):25112518

2. Kessler RC, Crum RM, Warner LA, Nelson CB, Schulenberg J, Anthony JC (1997) Lifetime co-occurrence of DSM-III-R alcohol abuse and dependence with other psychiatric disorders in the National Comorbidity Survey. Archives of general psychiatry. 54(4):313-321

3. Cleary M, Hunt G, Matheson S, Siegfried N, Walter G (2008) Psychosocial interventions for people with both severe mental illness and substance misuse. The Cochrane database of systematic reviews 1:Cd001088

4. Abou-Saleh MT, Ghubash R, Daradkeh TK (2001) A1 Ain Community Psychiatric Survey. I. Prevalence and socio-demographic correlates. Social psychiatry and psychiatric epidemiology. 36(1):20-28

5. De Graaf R, Bijl RV, Smit F, Vollebergh WA, Spijker J (2002) Risk factors for 12-month comorbidity of mood, anxiety, and substance use disorders: findings from the Netherlands Mental Health Survey and Incidence study. The American journal of psychiatry 159(4):620-629

6. Melartin TK, Rytsala HJ, Leskela US, Lestela-Mielonen PS, Sokero TP, Isometsa ET (2002) Current comorbidity of psychiatric disorders among DSM-IV major depressive disorder patients in psychiatric care in the Vantaa Depression Study. The Journal of clinical psychiatry. 63(2):126-134

7. Marsden J, Gossop M, Stewart D, Rolfe A, Farrell M (2000) Psychiatric symptoms among clients seeking treatment for drug dependence. Intake data from the National Treatment Outcome Research Study. The British journal of psychiatry: the journal of mental science. 176:285-289

8. Weissman MM, Myers JK, Harding PS (1980) Prevalence and psychiatric heterogeneity of alcoholism in a United States urban community. Journal of studies on alcohol. 41(7):672-681

9. Herz LR, Volicer L, D'Angelo N, Gadish D (1990) Additional psychiatric illness by Diagnostic Interview Schedule in male alcoholics. Comprehensive psychiatry. 31(1):72-79

10. Weiss KJ, Rosenberg DJ (1985) Prevalence of anxiety disorder among alcoholics. The Journal of clinical psychiatry. 46(1):3-5

11. Hesselbrock MN, Meyer RE, Keener JJ (1985) Psychopathology in hospitalized alcoholics. Archives of general psychiatry. 42(11):1050-1055

12. Helzer JE, Pryzbeck TR (1988) The co-occurrence of alcoholism with other psychiatric disorders in the general population and its impact on treatment. Journal of studies on alcohol. 49(3):219-224

13. Powell BJ, Penick EC, Othmer E, Bingham SF, Rice AS (1982) Prevalence of additional psychiatric syndromes among male alcoholics. The Journal of clinical psychiatry. 43(10):404-407

14. Powell BJ, Read MR, Penick EC, Miller NS, Bingham SF (1987) Primary and secondary depression in alcoholic men: an important distinction? The Journal of clinical psychiatry. 48(3):98-101
15. Ranjan JK, Asthana HS (2017) Prevalence of mental disorders in India and other South Asian countries. Asian Journal of Epidemiology 10:45-53

16. Baxter AJ, Charlson FJ, Cheng HG, Shidhaye R, Ferrari AJ, Harvey W (2016) Prevalence of mental, neurological, and substance use disorders in China and India: a systematic analysis. Whiteford Lancet Psychiatry 3(9):832-841

17. Debasish B, Siddharth S, Surendra KM (2013) Psychiatric comorbidity in patients with substance use disorders attending an addiction treatment center in India over 11 years: case for a specialized "dual diagnosis clinic". Journal Of Dual Diagnosis. 9(1):23-29

18. Balhara YPS, Gupta R, Lal R (2016) Time trend for substance use disorder and psychiatric disorders among patients seeking treatment from a dual diagnosis clinic of a tertiary care substance use disorder treatment centre in India. ASEAN Journal of Psychiatry 17(2):16-20

19. Kisore P, Narottam L, Trivedi JK, Dalal PK, Aga VM (1994) A study of comorbitidy in psychoactive substance dependent patients. Indian Journal of Psychiatry. 36(3):133-137

20. Kattukulathill S, Kallivayalil RA, George R, Kazhungil F (2015) Psychiatric comorbidity in alcohol dependence: a cross-sectional study in a tertiary care setting. Kerala Journal of Psychiatry 28(2):156-160

21. Cherukunnath P, Palayat AM, Divakaran B, Mohanchandran W (2016) Psychiatric comorbidity in alcohol dependent outpatients in tertiary care centre. Journal of medical science and clinical research. 4(3):9880-9890

22. Heramani Singh N, Sharma SG, Pasweth AM (2005) Psychiatric co-morbidity among alcohol dependants. Indian Journal of Psychiatry. 47(4):222-224

23. Vohra AK, Yadav BS, Khurana H (2003) A study of psychiatric comorbidity in alcohol dependence. Indian journal of psychiatry. 45(4):2

24. Gauba D, Thomas P, Balhara YPS, Smita Deshpande N (2016) Psychiatric comorbidity and physical correlates in alcohol dependent patients. Indian Journal of Psychoogical Medicine. 38(5):414-418

25. Nagendrappa AKB, Mallanna S, Sanjay Raj G (2018) Alcohol, gender, and psychiatric co-morbidity: a study from India. Iranian Journal Of Psychiatry And Behavioural Sciences 12(1):e9180

26. Nunes EV, Liu X, Samet S, Matseoane K, Hasin D (2006) Independent versus substance-induced major depressive disorder in substance-dependent patients: observational study of course during follow-up. The Journal of clinical psychiatry. 67(10):1561-1567

27. Hasin DS, Grant BF (2002) Major depression in 6050 former drinkers: association with past alcohol dependence. Archives of general psychiatry. 59(9):794-800

28. Ramsey SE, Kahler CW, Read JP, Stuart GL, Brown RA (2004) Discriminating between substance-induced and independent depressive episodes in alcohol dependent patients. Journal of studies on alcohol. 65(5):672-676

29. Davidson KM (1995) Diagnosis of depression in alcohol dependence: changes in prevalence with drinking status. The British journal of psychiatry. 166(2):199-204

30. Schuckit MA, Irwin M, Smith TL (1994) One-year incidence rate of major depression and other psychiatric disorders in 239 alcoholic men. Addiction (Abingdon, England) 89(4):441-445

31. Baving L, Olbrich $\mathrm{H}$ (1996) Anxiety in alcohol-dependent patients. Fortschritte der Neurologie-Psychiatrie. 64(3):83-89

32. Rounsaville BJ, Dolinsky ZS, Babor TF, Meyer RE (1987) Psychopathology as a predictor of treatment outcome in alcoholics. Archives of general psychiatry. 44(6):505-513

33. Hasin DS, Stinson FS, Ogburn E, Grant BF (2007) Prevalence, correlates, disability, and comorbidity of DSM-IV alcohol abuse and dependence in the United States: results from the National Epidemiologic Survey on Alcohol and Related Conditions. Archives of general psychiatry. 64(7):830-842

34. Alegria AA, Hasin DS, Nunes EV, Liu SM, Davies C, Grant BF et al (2010) Comorbidity of generalized anxiety disorder and substance use disorders: results from the National Epidemiologic Survey on Alcohol and Related Conditions. The Journal of clinical psychiatry 71(9):1187-1195 quiz 252-3

35. Burns L, Teesson M, O'Neill K (2005) The impact of comorbid anxiety and depression on alcohol treatment outcomes. Addiction (Abingdon, England) 100(6):787-796

36. Bruce SE, Yonkers KA, Otto MW, Eisen JL, Weisberg RB, Pagano M et al (2005) Influence of psychiatric comorbidity on recovery and recurrence in generalized anxiety disorder, social phobia, and panic disorder: a 12-year prospective study. The American journal of psychiatry. 162(6):1179-1187

37. Markowitz JS, Weissman MM, Ouellette R, Lish JD, Klerman GL (1989) Quality of life in panic disorder. Archives of general psychiatry. 46(11):984-992

38. Marshall JR (1994) The diagnosis and treatment of social phobia and alcohol abuse. Bulletin of the Menninger Clinic 58(2 Suppl A):A58-A66 
39. Bowen RC, Cipywnyk D, D'Arcy C, Keegan D (1984) Alcoholism, anxiety disorders, and agoraphobia. Alcoholism, clinical and experimental research. 8(1):48-50

40. Kessler RC, Birnbaum H, Demler O, Falloon IR, Gagnon E, Guyer M et al (2005) The prevalence and correlates of nonaffective psychosis in the National Comorbidity Survey Replication (NCS-R). Biologiological psychiatry. 58(8):668-676

41. Glass IB (1989) Alcoholic hallucinosis: a psychiatric enigma--1. The development of an idea. British journal of addiction. 84(1):29-41

42. Schuckit MA, Tipp JE, Reich T, Hesselbrock VM, Bucholz KK (1995) The histories of withdrawal convulsions and delirium tremens in 1648 alcohol dependent subjects. Addiction (Abingdon, England) 90(10):1335-1347

43. Soyka M (2008) Prevalence of delirium tremens. The American journal on addictions / American Academy of Psychiatrists in Alcoholism and Addictions. 17(5):452

44. Dixon L, Haas G, Weiden P, Sweeney J, Frances A (1990) Acute effects of drug abuse in schizophrenic patients: clinical observations and patients' selfreports. Schizophrenia bulletin. 16(1):69-79

45. Oquendo MA, Currier D, Liu SM, Hasin DS, Grant BF, Blanco C (2010) Increased risk for suicidal behavior in comorbid bipolar disorder and alcohol use disorders: results from the National Epidemiologic Survey on Alcohol and Related Conditions (NESARC). The Journal of clinical psychiatry. 71(7): 902-909

46. Johnson JG, Spitzer RL, Williams JB, Kroenke K, Linzer M, Brody D et al (1995) Psychiatric comorbidity, health status, and functional impairment associated with alcohol abuse and dependence in primary care patients: findings of the PRIME MD-1000 study. Journal of consulting and clinical psychology. 63(1):133-140

47. Lima AF, Pechansky F, Fleck MP, De Boni R (2005) Association between psychiatric symptoms and severity of alcohol dependence in a sample of brazilian men. The Journal of nervous and mental disease. 193(2):126-130

48. Schaefer MR, Sobieraj K, Hollyfield RL (1987) Severity of alcohol dependence and its relationship to additional psychiatric symptoms in male alcoholic inpatients. The American journal of drug and alcohol abuse. 13(4):435-447

49. Nanjayya SB, Hazari N, Elwadhi D, Basu D (2017) Prevalence of dual diagnosis among clinic attending patients in a de-addiction centre of a tertiary care hospital. Asian Journal Of Psychiatry 25:169-174

50. Kanika M, Chand PK, Marimuthu LN, Suman P (2017) Addiction severity and comorbidity among women with alcohol use disorders: a hospital-based study from India. Asian Journal Of Psychiatry 28:67-72

51. Sheehan DV, Lecrubier $Y$, Sheehan KH, Amorim P, Janavs J, Weiller E, Hergueta T, Baker R, Dunbar GC (1998) The Mini-International Neuropsychiatric Interview (M.IN.I.): the development and validation of a structured diagnostic psychiatric interview for DSM-IV and ICD-10. J Clin Psychiatry. 59(20):22-33

52. Brown SA, Inaba RK, Gillin JC, Schuckit MA, Stewart MA, Irwin MR (1995) Alcoholism and affective disorder: clinical course of depressive symptoms. The American journal of psychiatry. 152(1):45-52

53. Bucholz KK, Cadoret R, Cloninger CR, Dinwiddie SH, Hesselbrock VM, Nurnberger JI Jr et al (1994) A new, semi-structured psychiatric interview for use in genetic linkage studies: a report on the reliability of the SSAGA. Journal of studies on alcohol. 55(2):149-158

54. Roberts MC, Emsley RA, Pienaar WP, Stein DJ (1999) Anxiety disorders among abstinent alcohol-dependent patients. Psychiatric services (Washington, DC) 50(10):1359-1361

55. Schuckit MA, Tipp JE, Bergman M, Reich W, Hesselbrock VM, Smith TL (1997) Comparison of induced and independent major depressive disorders in 2,945 alcoholics. The American journal of psychiatry. 154(7):948-957

56. Driessen MV (Feb 1998) Clemens; Wetterling, Tilman; John, Ulrich. Axis I and axis II comorbidity in alcohol dependence and the two types of alcoholism. Alcoholism: Clinical and Experimental Research. 22(1):77-86

57. O'Sullivan K, Rynne C, Miller J, O'Sullivan S, Fitzpatrick V, Hux M et al (1988) A follow-up study on alcoholics with and without co-existing affective disorder. The British journal of psychiatry : The journal of mental science. 152:813-819

58. Hasin DS, Grant BF, Endicott J (1988) Lifetime psychiatric comorbidity in hospitalized alcoholics: subject and familial correlates. The International journal of the addictions. 23(8):827-850

\section{Publisher's Note}

Springer Nature remains neutral with regard to jurisdictional claims in published maps and institutional affiliations.

\section{Submit your manuscript to a SpringerOpen ${ }^{\circ}$ journal and benefit from:}

- Convenient online submission

- Rigorous peer review

- Open access: articles freely available online

- High visibility within the field

- Retaining the copyright to your article

Submit your next manuscript at $\boldsymbol{\nabla}$ springeropen.com 